\title{
Determination of machining errors caused by dynamic deformations from process equipment
}

\author{
Aleksandr Starikov ${ }^{1, *}$, Ulyana Putilova ${ }^{1}$, and Olga Tempel $^{1}$ \\ ${ }^{1}$ Tyumen Industrial University, Department of "Technology of Mechanical Engineering", Tyumen, \\ Russia
}

\begin{abstract}
A method for determining and inputting the correction value is presented based on the data obtained as a result of the diagnosis of a $\mathrm{CNC}$ milling machine during machining curvilinear surfaces.
\end{abstract}

The accuracy of manufacturing items of general engineering, to a great extent, depends on the technological accuracy of the equipment on which they are manufactured. According to GOST 8-82, there are five accuracy classes for universal machines, but for CNC machines the use of such a classification is not advisable due to a number of features, in particular, due to the presence of not only a mechanical but also an electrical component in the positioning of the tool during machining.

GOST 22267-76 regulates the schemes and standards for testing the mechanical part of the spindle unit of milling metalworking machines by the following parameters: axial runout of the milling spindle; face runout of the spindle support face (for machines with milling cutters along the end face); radial runout of the outer centering surface of the spindle (for machines with centering of milling cutters along the outer centering surface); radial runout of the tapered bore of the milling spindle [1].

The same GOST prescribes actions aimed at checking the accuracy of movement of the moving elements of the machine (table, etc.).

Enterprises, the main activities of which are commissioning, routine maintenance and repair, develop their own schemes for testing the machines, depending on their purpose and layout.

These two methods are similar by the fact that diagnostics and all accuracy tests are performed on equipment without taking into account the loads that arise during the machining process. These include the pressing of the tool due to the forces of cutting and its wear, thermal deformation of the process system, accumulated errors in the CNC system, etc. [2].

Figure 1 presents a diagram of the errors of the basic shaping units of a CNC milling machine that arise during translational and rotational motions. These include linear position errors that determine the positioning error $\delta \mathrm{x}$ in the direction of motion and the errors $\delta \mathrm{y} \delta \mathrm{z}$ characterizing deviation from straightness in two mutually perpendicular directions, which in turn leads to the appearance of angular deviations in the movement of the table. Thus, with respect to the $\mathrm{X}$ axis, an error $\delta \varphi(\mathrm{x})$ appears, which is related to the errors of the bodies of revolution. With respect to the transverse and vertical axes, the errors are $\delta \varphi(y)$ and $\delta \varphi(z)$,

\footnotetext{
${ }^{*}$ Corresponding author: hapsai@rambler.ru
} 
respectively, which are related mainly to the shape and position errors of the guides, with due regard to the rigidity of the machine.

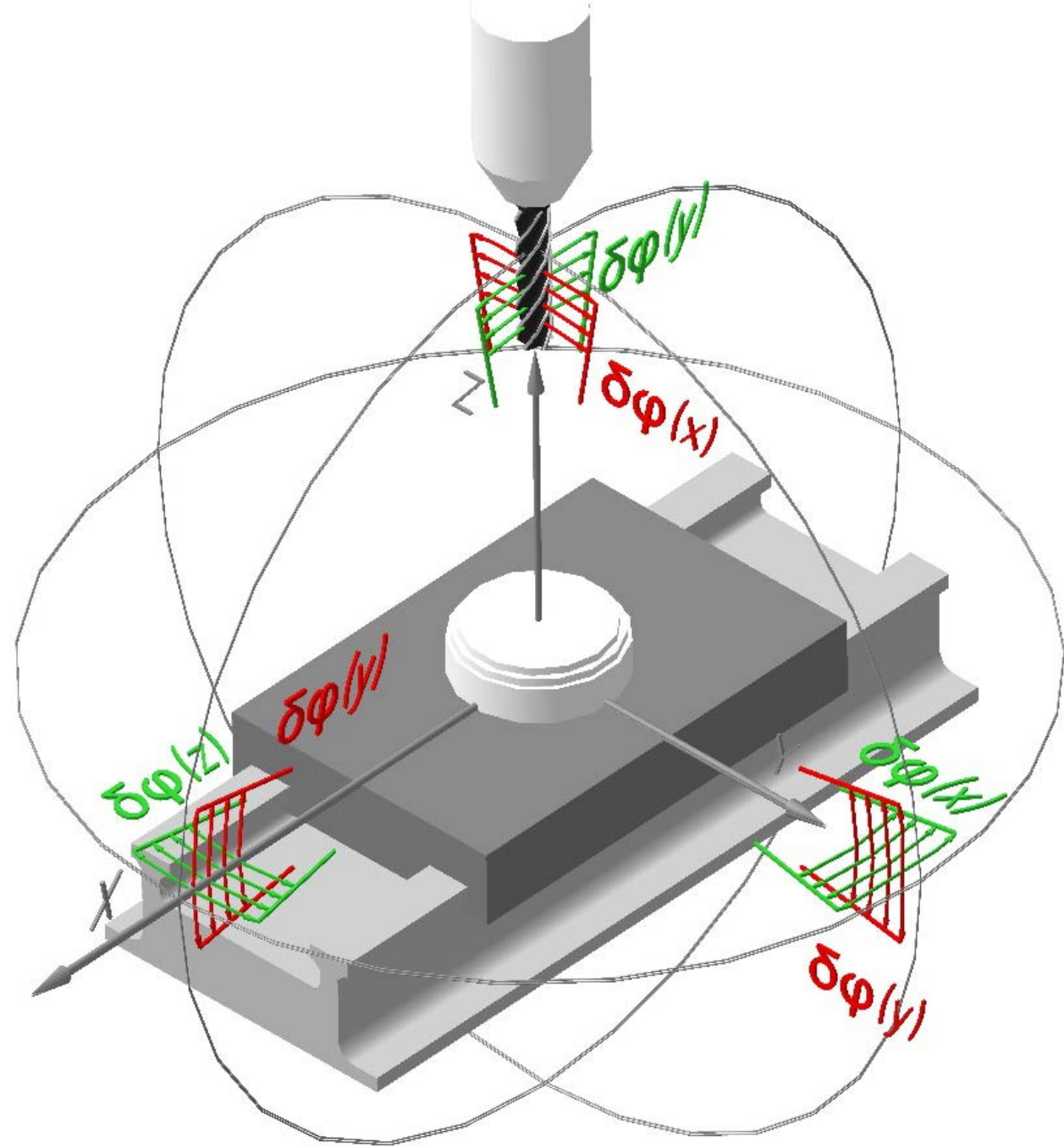

Fig. 1. Errors resulting from the translational and rotational motion of the shaping units of the CNC milling machine

In addition to linear ones, the angular errors associated with the positioning accuracy $\delta \varphi(\mathrm{z})$ and the misalignment of the $\mathrm{X}$ and $\mathrm{Y}$ axes - $\delta \varphi(\mathrm{x})$ and $\delta \varphi(\mathrm{y})$, respectively, also arise.

To confirm the above, an idealized model of an item and a control program was developed in the CAD CAM system Siemens NX. Visualization of the machining process according to the program on the CNC machine is shown in Fig. 2. 


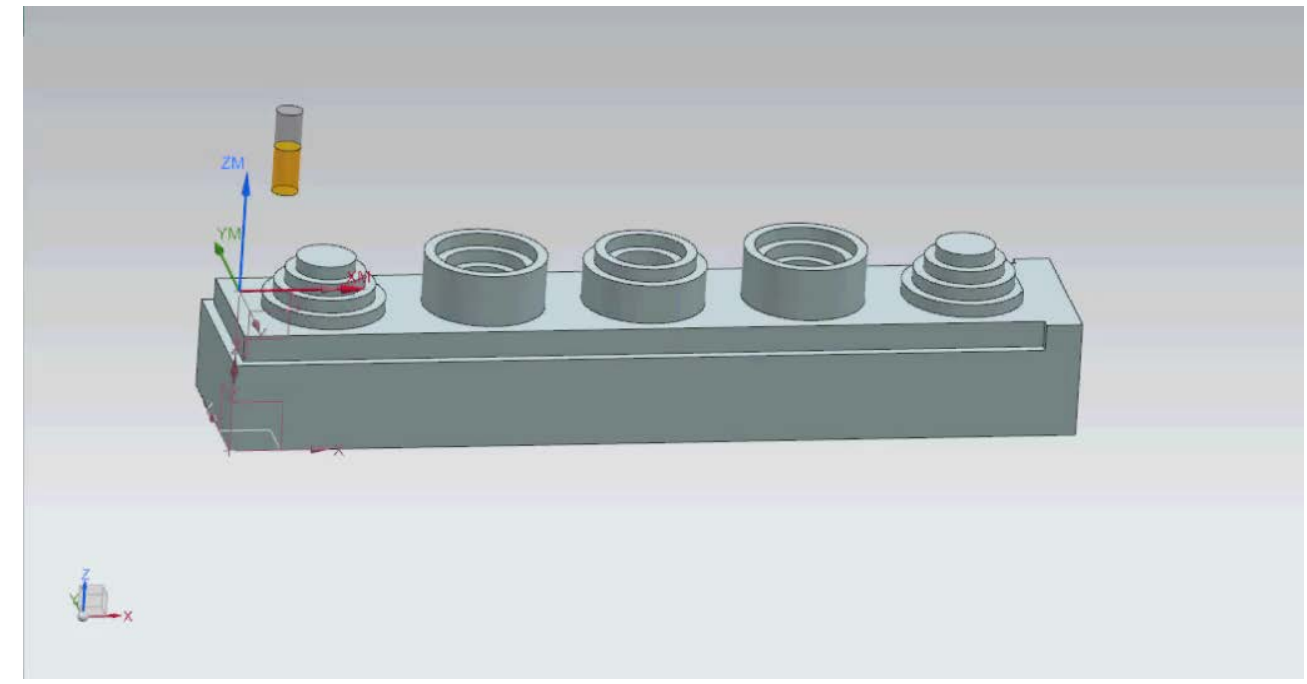

Fig. 2. Visualization of the process of machining an idealized model on a CNC machine VDL-500

The workpiece was machined (Fig. 3) using a VDL-500 CNC milling machine, with an end carbide mill (IC900) with a diameter of $\varnothing 14$; the workpiece material was a grade $40 \mathrm{X}$ steel with a Brinell hardness in the delivery state not $217 \mathrm{HB}$; a billet was a square bar iron $80 \times 80$. The machine was pre-tested for accuracy according to the method described in GOST 22267-76. The tests showed that all tested parameters correspond to the machines of class B, and by some characteristics exceed them. The test results are shown in Table 1 .

Table 1. Tests results of the CNC milling machine VDL-500

\begin{tabular}{|c|c|c|c|}
\hline \multirow[t]{2}{*}{ No. } & \multirow[t]{2}{*}{ Operation } & \multicolumn{2}{|c|}{ Data } \\
\hline & & Tolerance, $\mathrm{mm}$ & Check, mm \\
\hline 1 & 2 & 3 & 4 \\
\hline \multirow[t]{4}{*}{1} & \multirow[t]{4}{*}{ Plane-parallelism of the table surface } & \multicolumn{2}{|c|}{$\mathrm{X}-\mathrm{Z}$ plane } \\
\hline & & 0.06 & 0.05 \\
\hline & & \multicolumn{2}{|c|}{ Y-Z plane } \\
\hline & & 0.06 & 0.05 \\
\hline \multirow[t]{2}{*}{2} & \multirow{2}{*}{$\begin{array}{l}\text { Straightness of movement in the } \\
\text { direction of movement of the } \mathrm{X} \text { axis }\end{array}$} & \multicolumn{2}{|c|}{$\mathrm{X}-\mathrm{Y}$ plane } \\
\hline & & 0.015 & 0.01 \\
\hline \multirow[t]{2}{*}{3} & \multirow{2}{*}{$\begin{array}{l}\text { Straightness of movement in the } \\
\text { direction of movement of the } \mathrm{Y} \text { axis }\end{array}$} & \multicolumn{2}{|c|}{$\mathrm{X}-\mathrm{Y}$ plane } \\
\hline & & 0.015 & 0.01 \\
\hline 4 & $\begin{array}{l}\text { Parallelism of the table surface of the } \\
\mathrm{X} \text { axis }\end{array}$ & 0.015 & 0.01 \\
\hline 5 & $\begin{array}{l}\text { Parallelism of the table surface of the } \\
\text { Y axis }\end{array}$ & 0.015 & 0.01 \\
\hline 6 & $\begin{array}{l}\text { Parallelism of the T-slot of the } \mathrm{X} \text { axis } \\
\text { table }\end{array}$ & 0.015 & 0.01 \\
\hline \multirow[t]{6}{*}{7} & \multirow{6}{*}{$\begin{array}{l}\text { Perpendicularity relative to the main } \\
\text { movement along each of the axes }\end{array}$} & \multicolumn{2}{|c|}{$\mathrm{X}-\mathrm{Z}$ plane } \\
\hline & & $0.02 / 500$ & $0.01 / 500$ \\
\hline & & \multicolumn{2}{|c|}{ Y-Z plane } \\
\hline & & $0.02 / 500$ & $0.01 / 500$ \\
\hline & & \multicolumn{2}{|c|}{$\mathrm{X}-\mathrm{Y}$ plane } \\
\hline & & 0.02 & $0.01 / 500$ \\
\hline 8 & & \multicolumn{2}{|c|}{$\mathrm{X}-\mathrm{Z}$ plane } \\
\hline
\end{tabular}




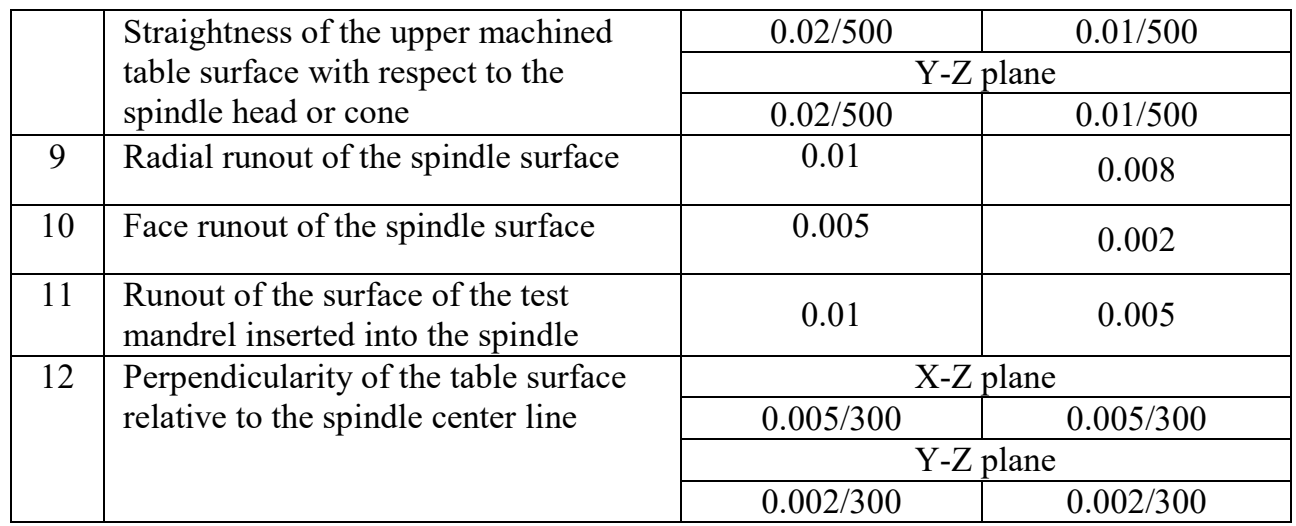

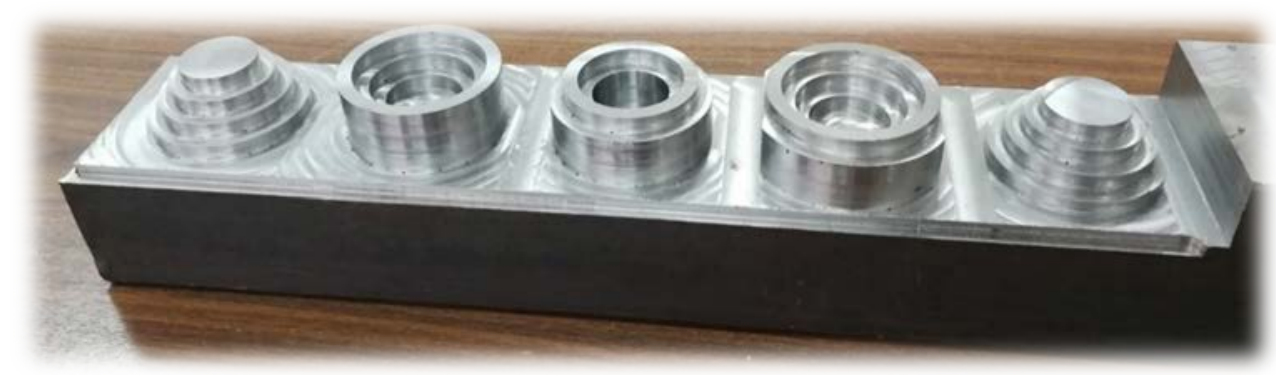

Fig. 3. Parts after machining on the CNC machine VDL-500

According to the procedure described in [3], in order to check the part after its manufacture, the EOS COORD $3 \mathrm{CNC}$ control and measuring machine with the RENISHAW MH20i contactor was used, the measurements were made using the $3 \mathrm{D}$ idealized model shown in Fig. 4.

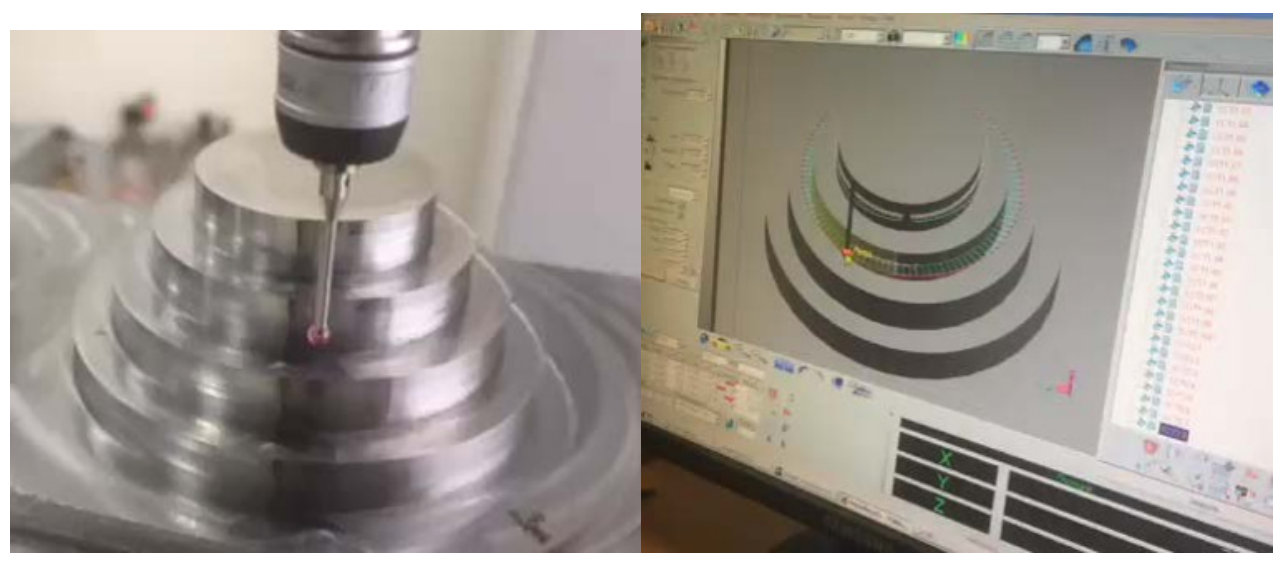

Fig. 4. Checking the accuracy of the workpiece on the $\mathrm{CNC}$ control and measuring machine.

As can be seen from the diagram of the measurement results shown in Figure 5, all the measurements are outside the tolerance range, in the diagram they are marked as gray lines, deviations are $\pm 0.05 \mathrm{~mm}$. 



Fig. 5. Results of measured circles.

From the data of the circular plot, a dip in the measurements is visible repeated on each measured circle and is shown in more detail in Figure 6.

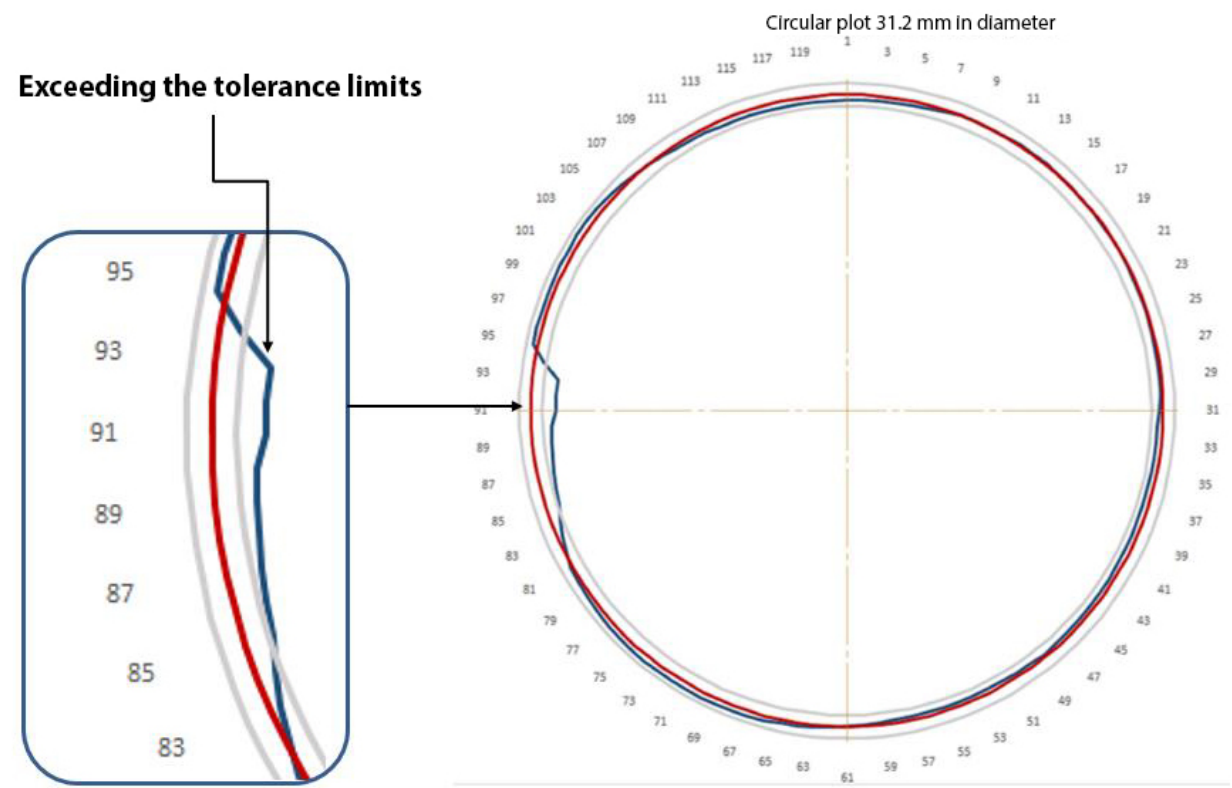

Fig. 6. Circular plot of the measurement results.

Exceeding the limits of the tolerance range of the executable size, in this case, characterizes the influence of elastic deformations arising during the cutting process on the accuracy of the workpiece. The dip is caused by the entrance and exit of the tool from the "double tool pass" cutting zone. To determine the errors of the process system caused by the appearance of elastic deformations arising during the cutting process, we divide the circle into sectors and determine the area of the sector of the problem area by the formula 1: 


$$
S_{n}=\frac{1}{2} \sum_{i=1}^{n} \overline{\rho_{l}^{2}} \Delta \varphi_{i}
$$

where: $S_{n}$ - area of the n-th section;

$\overline{\rho_{l}}$ - length of the radius vector;

$\Delta \varphi_{i}$ - central angle.

At the same time, the height of the sector will be the amount of compensation on the arc of this sector. Correction is entered if the error value is outside the tolerance range. The more sectors, the more often it is possible to enter compensation into the tool diameter parameter.

In contrast to the method of introducing corrections into the trajectory of the tool described in [4], it is proposed to use an existing corrector for the diameter of the cutting tool. The machine CNC system provides a corrector for the diameter of the cutting tool $\mathrm{Di}$, the value of which is stored in a special area of memory. The trajectory of the tool is set by equidistant relative to this parameter by the value of the tool radius. Using the simplest algorithm, it is possible to introduce an external operator with a reference to determine the value of the correction value from a matrix prepared in advance based on the diagnostic data, thereby, at any time, it is possible to input a correction for the diameter of the tool.

The amount of compensation acting on a certain sector is determined by the formula (2) determining the area of the trapezoid, which is formed as a result of the intersection of the two triangles of the sector, the first is the idealized triangle, the second is the actual one (obtained as a result of the measurement).

$$
h=\frac{\sum_{i=1}^{n}\left(\overline{\rho_{l}^{2}}-\overline{r_{l}^{2}}\right) \Delta \phi_{i}}{(a+b)},
$$

The diameter parameter of the cutting tool must be corrected by the trapezoid height value, thereby leveling the errors arising during the manufacturing process caused by the elastic deformations of the process system.

In the course of the performed work, a method for determining the errors in the process system of a CNC milling machine has been developed, and a method for compensating errors using a mathematical model for determining the compensation value has been determined. The proposed solutions make it possible to manufacture items with the required accuracy even under condition of partial wear of some elements of the spindle unit.

\section{References}

1. R.Y. Nekrasov, U.S. Putilova, A.I. Starikov, D.A. Kharitonov, Diagnostics of cut-layer deformation and rational tool loading in numerically controlled lathes, Russian engineering research, 2014, Vol. 34, No. 12, pp. 826-828 (2014)

2. R.Y. Nekrasov, U.S. Putilova, I.V. Soloviev, Laser interferometry method of stress determination in loaded cutting tool parts, Applied Mechanics and Materials Vol. 698 pp. $537-541$ (2015)

3. R.Y. Nekrasov, A.I. Starikov, Lasukov A.A, Entering the operative correction machining processes $C N C$, IOP Conf. Series: Materials Science and Engineering 91 (2015)

4. R.Y. Nekrasov, A.I. Starikov, Lasukov A.A, Diagnosis of the computer-controlled milling machine, definition of the working errors and input corrections on the basis of mathematical, IOP Conf. Series: Materials Science and Engineering Volume 154 (2016) 